\title{
Article
}

\section{Fire smoke toxicity: The effect of nitrogen oxides}

Paul, K, Hull, T Richard, Lebek, K and Stec, Anna A

Available at http://clok.uclan.ac.uk/1072/

Paul, K, Hull, T Richard ORCID: 0000-0002-7970-4208, Lebek, K and Stec, Anna A ORCID: 0000-0002-6861-0468 (2008) Fire smoke toxicity: The effect of nitrogen oxides. Fire Safety Journal, 43 (4). pp. 243-251. ISSN 0379-7112

It is advisable to refer to the publisher's version if you intend to cite from the work. http://dx.doi.org/10.1016/j.firesaf.2007.10.003

For more information about UCLan's research in this area go to http://www.uclan.ac.uk/researchgroups/ and search for <name of research Group>.

For information about Research generally at UCLan please go to http://www.uclan.ac.uk/research/

All outputs in CLoK are protected by Intellectual Property Rights law, including Copyright law. Copyright, IPR and Moral Rights for the works on this site are retained by the individual authors and/or other copyright owners. Terms and conditions for use of this material are defined in the policies page.

\section{CLoK}

Central Lancashire online Knowledge www.clok.uclan.ac.uk

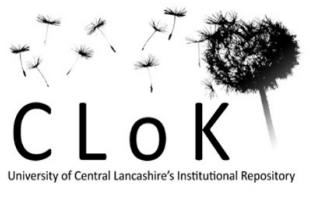


Fire Safety Journal, Vol. 43, p. 243-251, 2008.

\title{
FIRE SMOKE TOXICITY: THE EFFECT OF NITROGEN OXIDES.
}

\author{
K T Paul, T. R. Hull, K.Lebek, A. A. Stec,
}

\begin{abstract}
.
Measurements of the toxic potency of fire effluents are required for fire safety engineering and fire hazard assessments. Toxic potency values may be generated using chemical analysis data and, or by animal protocols. The current ISO methods of calculating toxic potency values from chemical analysis data assume that the nitrogen oxides present in inhaled fire effluents are nitrogen dioxide, a highly irritant acid gas. Observations from real scale fire tests and bench scale tests which simulate the different fire stages show that, in some situations and particularly in proximity of the fire, the nitrogen oxides will be predominately nitric oxide but this can gradually change to nitrogen dioxide as the effluent moves away from the fire. Nitric oxide has a very different toxic potency and effect when compared to nitrogen dioxide. This paper considers the formation of nitric oxide and nitrogen dioxide in fire effluents, their potential toxic effects and the consequential need to reconsider the methods of calculating toxic potency values.
\end{abstract}

\section{Determination and application of toxic potency data.}

Fire Risk Assessments and Fire Safety Engineering are increasingly used in the design and assessment of enclosures. One essential input for these is a measure of the toxic potency of fire effluents and required data may be generated using chemical analysis and, or, animal protocols (1).

There is an increasing tendency to use chemical analysis methods especially in the European Union where regulations prevent the use of animal testing for all except very limited applications which do not include fire testing (2). Chemical analysis data are used to calculate toxic potency values using equations such as those of ISO 13344 (3) and ISO TS 13571 (4). These methods calculate the toxic potency of fire effluents in terms of the narcotic gases, carbon dioxide $\left(\mathrm{CO}_{2}\right)$, carbon monoxide $(\mathrm{CO})$, hydrogen cyanide (HCN) and oxygen depletion $\left(\Delta \mathrm{O}_{2}\right)$, and irritant gases including hydrogen chloride $(\mathrm{HCl})$, hydrogen bromide $(\mathrm{HBr})$, hydrogen fluoride $(\mathrm{HF})$, sulphur dioxide $\left(\mathrm{SO}_{2}\right)$, nitrogen oxides $\left(\mathrm{NO}_{\mathrm{x}}\right)$, formaldehyde, acrolein and other organo 
irritants. In current ISO documents, all oxides of nitrogen $\left(\mathrm{NO}_{\mathrm{x}}\right)$ are considered to be nitrogen dioxide $\left(\mathrm{NO}_{2}\right)$.

In essence, methods of calculating toxic potency use the sum of the ratios of gas concentrations to values known, for example, to cause incapacitation or death to persons exposed for a defined time. Equations 1 and 2 are examples of these but other equations have also been published (3)(4).

In equation $1(3)$, the factors ' $m$ ' and ' $b$ ' relate to the increased ventilation rate caused by carbon dioxide.

$$
\mathrm{FED}=\frac{m[\mathrm{CO}]}{\left[\mathrm{CO}_{2}\right]-b}+\frac{21-\left[\mathrm{O}_{2}\right]}{21-\mathrm{LC}_{50, \mathrm{O}_{2}}}+\frac{[\mathrm{HCN}]}{\mathrm{LC}_{50, \mathrm{HCN}}}+\frac{[\mathrm{HCl}]}{\mathrm{LC}_{50, \mathrm{HCl}}}+\frac{[\mathrm{HBr}]}{\mathrm{LC}_{50, \mathrm{HBr}}}+\ldots
$$

\section{Equation 1}

In equation 2 (3), the effect of the increased ventilation rate caused by carbon dioxide is applied by multiplying both the narcotic and irritant terms by the factor $\mathrm{V}_{\mathrm{CO} 2}$. The term ' $\mathrm{A}$ ' relates to the formation of acidosis.

$$
\mathrm{FED}=\left\{\frac{[\mathrm{CO}]}{\mathrm{LC}_{50, \mathrm{CO}}}+\frac{[\mathrm{HCN}]}{\mathrm{LC}_{50, \mathrm{HCN}}}+\frac{[\mathrm{HCl}]}{\mathrm{LC}_{50, \mathrm{HCl}}}+\ldots . . \times \mathrm{V}_{\mathrm{CO}_{2}}+\mathrm{A}+\frac{21-\left[\mathrm{O}_{2}\right]}{21-5.4}\right.
$$

where $\mathrm{V}_{\mathrm{CO}_{2}}=1+\frac{\exp \left(0.14\left[\mathrm{CO}_{2}\right]\right)-1}{2}$

and $\mathrm{A}$ is an acidosis factor equal to $\left[\mathrm{CO}_{2}\right] \times 0.05$.

\section{Equation 2}

In both equations, the $\mathrm{LC}_{50}$ values are reference concentrations of gases which cause death when inhaled for a specified time, typically 30 minutes. This is widely used but other reference values may be used to determine effects such as incapacitation, etc. Additional terms may be used to include the effects of other irritant gases.

Recent work using Fourier Transform Infra Red (FTIR) to analyze fire effluents has shown that the nitrogen oxides in fire effluents may be predominately nitric oxide (NO) (5)(6)(7) and that this gas may be relatively stable at low concentrations and at temperatures of inhaled fire effluents. Further evidence that nitric oxide can exist as a gas at low concentrations and temperatures is shown by its 
increasing use to treat persons with lung disorders (8) (9). Nitric oxide is also a major component in tobacco smoke (10) (11) (12) (13) (14) and motor vehicle exhaust gases (15).

Nitrogen dioxide $\left(\mathrm{NO}_{2}\right)$ is a gaseous acid anhydride, is highly soluble in water and forms a highly acidic irritant. In contrast, nitric oxide exhibits complex toxic effects and essentially causes vasodilation and passes into the bloodstream (8).

\section{Formation of Nitrogen Oxides in Fire.}

The nitrogen containing fire gases most frequently listed in fire smoke toxicity tests are hydrogen cyanide, nitrogen oxides $\left(\mathrm{NO}_{\mathrm{x}}\right)$ and, less frequently, ammonia, acrylonitrile, organo-nitriles and isocyanates (3) (4) (16).

Nitric oxide is formed at fire temperatures by the direct combination of nitrogen and oxygen and by the combustion of organic compounds containing nitrogen. The former reaction, at temperatures above $1200^{\circ} \mathrm{C}$, was used in a now obsolete industrial process to manufacture nitric oxide (17). At lower temperatures, active hydrocarbon units can react with atmospheric nitrogen to form hydrogen cyanide which is rapidly oxidized to nitric oxide (18). Chemistry textbooks suggest that at temperatures of less than $200^{\circ} \mathrm{C}$, nitric oxide reacts with oxygen in the air (17) (19) and thus all nitrogen oxides in fire effluents are considered to be nitrogen dioxide. The analytical techniques used to determine nitrogen oxides in fire effluents may not distinguish between the different nitrogen oxides and present results as though it was all nitrogen dioxide (20).

The use of FTIR to analyze fire effluent samples not only showed the necessity to determine nitric oxide and nitrogen dioxide separately (23), but also that at typical effluent sampling and determining temperatures $\left(150\right.$ to $\left.180^{\circ} \mathrm{C}\right)$, most of the nitrogen oxides $(>95 \%)$ are present as nitric oxide. In practice, it is rarely possible to identify nitrogen dioxide with certainty as its concentrations are very low and close to the lower detection limit of less than 5ppm (5) (6) (7).

Figure 1 shows the nitric oxide and nitrogen dioxide concentration/time curves for a fire test in the ISO room (22). The gases were determined using chemiluminescence and the results show that the nitrogen oxides are predominantly nitric oxides with very little nitrogen dioxide. Similar results were obtained using FTIR analysis. Toxfire (22) gives similar results for a number of different materials 
burning under different ventilation conditions. Figures $2 \mathrm{a}$ and $2 \mathrm{~b}$ show the relationship between equivalence ratio and the volumetric yields of nitric oxide and nitrogen dioxide for the real scale fire tests with different ventilation openings in the ISO Room for polypropylene (Figure 2a) and for nylon 6.6 (Figure 2b) (22).

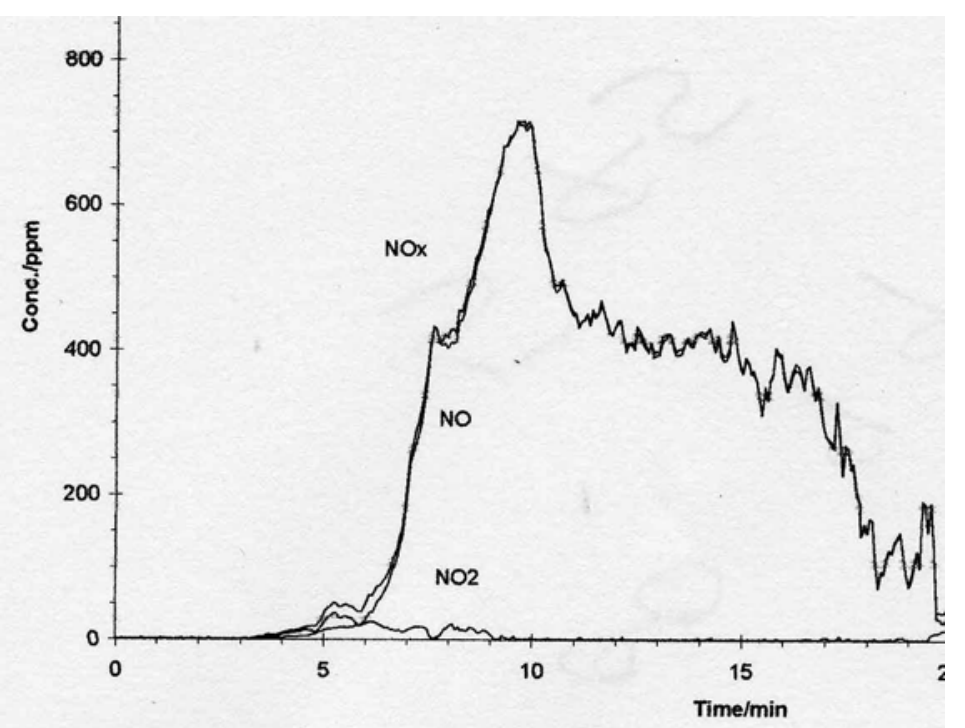

Figure 1. Nitric Oxide and Nitrogen Dioxide Concentration/time Curves for Real Scale Fire Test in ISO Room burning Tetramethylthiuram monosulphide. Gases determined using Chemiluminescence. (22)
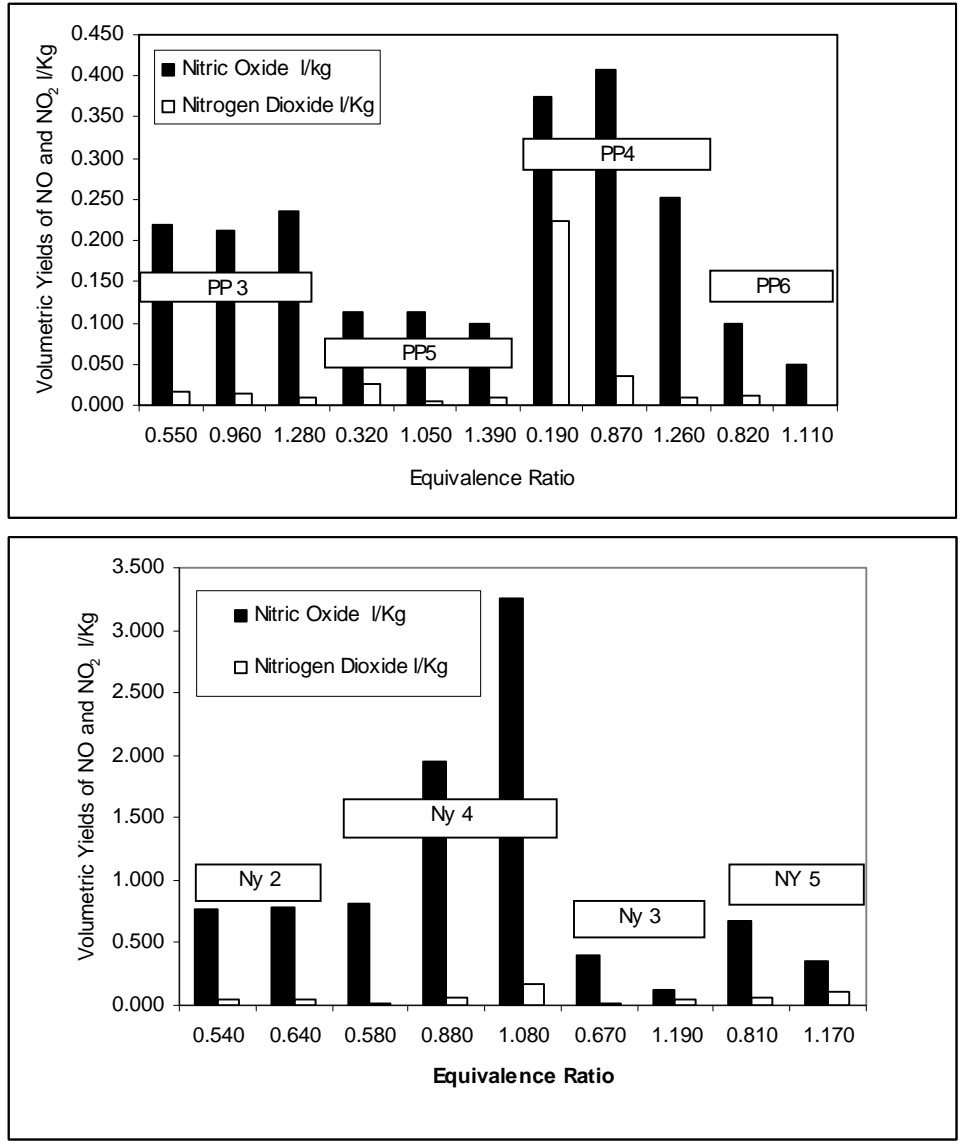

Figure 2. Relationship between Equivalence Ratio and Volumetric Yields of Nitric Oxide and Nitrogen Dioxide for Real Scale Fire Tests with Different Ventilation Openings in the ISO Room (22).

Figure 2a, Polypropylene: ventilation area increases from PP3 to PP5 to PP4 to PP6.

Figure 2b, Nylon 6.6:

ventilation area increases from $\mathrm{Ny}$ 2 to Ny 4 to Ny 3 to Ny 5 . 
Table 1a gives the results of tests using the apparatus of IEC 60695-7-50, steady state tube furnace type tests. Nitric oxide was the predominant nitrogen oxide with concentrations of typically 160ppm or less. Relatively low concentrations of nitrogen dioxide were detected but in many tests it was not detected and can therefore be assumed to be less than the detection limit $(<5 \mathrm{ppm})$. Although these results are not from real scale tests, it can be argued that the IEC 60695-50,51 (23) (24) and ISO TS 19700 (25) tests simulate real fire conditions as temperatures and equivalence ratios are selected and replicated to comply with the different fire stages identified by ISO (1).

\begin{tabular}{|c|c|c|c|c|}
\hline \multirow{3}{*}{$\begin{array}{c}\text { Fire Ventilation } \\
\text { Furnace } \\
\text { Temperature } \\
{ }^{\circ} \mathrm{C}\end{array}$} & \multicolumn{2}{|c|}{$\begin{array}{c}\text { Well ventilated } \\
\text { Equivalence Ratio }<1\end{array}$} & \multicolumn{2}{|c|}{$\begin{array}{c}\text { Vitiated } \\
\text { Equivalence Ratio }>1\end{array}$} \\
\hline & \multicolumn{4}{|c|}{ Fire effluent concentrations ppm } \\
\hline & $\begin{array}{l}\text { Nitric } \\
\text { Oxide }\end{array}$ & $\begin{array}{c}\text { Nitrogen } \\
\text { Dioxide }\end{array}$ & $\begin{array}{l}\text { Nitric } \\
\text { Oxide }\end{array}$ & $\begin{array}{c}\text { Nitrogen } \\
\text { Dioxide }\end{array}$ \\
\hline \multicolumn{5}{|c|}{ Rigid Polyurethane Foam } \\
\hline 650 & 160 & $<5$ & 40 & $<5$ \\
\hline 650 & 70 & $<5$ & & \\
\hline 825 & & & 14 & $<5$ \\
\hline \multicolumn{5}{|c|}{ Epoxy laminate } \\
\hline 650 & 12 & $<5$ & 75 & $<5$ \\
\hline 825 & & & 45 & $<5$ \\
\hline \multicolumn{5}{|c|}{ Nylon 6.6} \\
\hline 650 & 86 & 5 & 45 & 11 \\
\hline \multicolumn{5}{|c|}{ MDF } \\
\hline 650 & 84 & 8 & 33 & 15 \\
\hline \multicolumn{5}{|c|}{ FR MDF } \\
\hline 900 & 37 & 10 & & \\
\hline
\end{tabular}

Table 1a. Typical Nitric Oxide and Nitrogen Dioxide Concentrations for Compounds tested to IEC 60695-7-50 and ISO TS 19700, Steady State Tube Furnace Methods.

Table $1 \mathrm{~b}$ shows the fire effluent temperatures at various positions within the mixing chamber of the ISO 60695-7-50 and ISO TS 19700 tests. The thermocouples are on a vertical axis, in above and below the furnace tube exit. The $75 \mathrm{~mm}$ thermocouple was at the centre of the tube exit. These data show that, with the exception of the effluent near the furnace tube exit, the fire effluent within the mixing chamber is less than 60 to $66^{\circ} \mathrm{C}$ for well ventilated fire stages and less than 36 to $48^{\circ} \mathrm{C}$ for vitiated fire stages. 
The data in tables $1 \mathrm{a}$ and $1 \mathrm{~b}$ show that at 36 to $66^{\circ} \mathrm{C}$, nitric oxide is the main nitrogen oxide present in the fire effluents.

\begin{tabular}{ccccccc}
$\begin{array}{c}\text { Test Conditions } \\
\text { Set Furnace } \\
\text { Temperature }\end{array}$ & $\begin{array}{c}\text { Primary } \\
\text { Air Flow } \\
\begin{array}{l}{ }^{\circ} \mathbf{C} \\
\text { 1/min }\end{array}\end{array}$ & Fire Stage & $\begin{array}{c}\text { Test } \\
\text { Material }\end{array}$ & \multicolumn{2}{c}{$\begin{array}{c}\text { Effluent Temperature } \\
\text { in mixing chamber C }\end{array}$} \\
$\begin{array}{c}\text { Height of Thermocouple } \\
\text { above base of chamber } \\
750\end{array}$ & 15 & Well Ventilated & None & 175 to & 251 & 68 to 73 \\
750 & 4 & Vitiated & None & 134 to 88 & 34 to 43 \\
750 & 15 & Well Ventilated & Polypropylene & 226 to 142 & 60 to 66 \\
750 & 4 & Vitiated & Polypropylene & 146 to 114 & 36 to 48
\end{tabular}

Table 1b. Typical Fire Effluent Temperatures in IEC 60695-7-50, 50 and ISO TS 19700 Bench Scale Tests.

The results of cone calorimeter tests to ISO 5660 (26), given in table 2, also show that the nitrogen oxides in these well ventilated fire effluent are predominately nitric oxide.

\begin{tabular}{|c|c|c|c|c|c|c|c|}
\hline \multirow{2}{*}{$\begin{array}{l}\text { Cone Calorimeter } \\
\text { Fire Stage }\end{array}$} & $\begin{array}{c}\text { Heat Flux } \\
\mathbf{k W} / \mathbf{m}^{2}\end{array}$ & $\begin{array}{l}\text { Air Flow } \\
1 / \min \end{array}$ & $\begin{array}{l}\text { Std PU } \\
\text { Foam }\end{array}$ & $\begin{array}{l}\text { HRPU } \\
\text { Foam }\end{array}$ & $\begin{array}{c}\text { CHMRPU } \\
\text { Foam }\end{array}$ & $\begin{array}{l}\text { FRPU } \\
\text { Foam }\end{array}$ & $\begin{array}{c}\text { MF/PF } \\
\text { Laminate }\end{array}$ \\
\hline & & & \multicolumn{5}{|c|}{ Nitric oxide concentration ppm } \\
\hline \multirow{3}{*}{$\begin{array}{c}\text { 2, Growth } \\
\text { Well ventilated }\end{array}$} & 35 & $241 / \mathrm{s}$ & 70 & 40 & 75 & 24 & 22 to 27 \\
\hline & & & \multicolumn{5}{|c|}{ Nitrogen Dioxide concentration ppm } \\
\hline & & & $<5$ & $<5$ & $<5$ & $<5$ & $<5$ \\
\hline
\end{tabular}

Table 2. Typical Nitric Oxide and Nitrogen Dioxide Concentrations for Compounds tested to ISO 5660, Cone Calorimeter Test (26).

Inspection of results from the IMO smoke box test (27) shows only a few instances when nitrogen dioxide has been found in amounts above the limit of detection of FTIR (28). The cabinet temperature is typically about 40 to $60^{\circ} \mathrm{C}$ at the end of a test. Although these results were obtained using FTIR with gas sampling temperatures of 160 to $180^{\circ} \mathrm{C}$, it is considered that the gas sampling temperature will have a minor effect because of the high gas sampling rates typically used.

\section{Toxicity of Nitric Oxide and Nitrogen Dioxide.}

Nitric Oxide is a free radical and can exist in different forms. The literature reports that since the 1980 's, low concentrations of nitric oxide gas have been 
increasingly used to in the treatment of adult respiratory distress syndrome, primary pulmonary hypertension, acute pulmonary hypertension pulmonary embolism, chronic obstructive pulmonary disease and pulmonary fibrosis, bronchodilation, persistent pulmonary hypertension of the newborn, congenital diaphragmatic hernia, congenital heart disease, idiopathic pulmonary hypertension, and also in adult and pediatric cardiac surgery and in cardiac and lung transplants. (8).

When inhaled at low concentrations, nitric oxide essentially induces vasodilation and especially pulmonary vasodilation and hence improve the blood supply in the lungs, reduces blood pressure and improves oxygen levels in the bloodstream. Nitric oxide in gaseous form causes vasodilation of blood vessels in the lung area that actively participates in the exchange of oxygen and carbon dioxide. (8).

Nitric oxide passes quickly into the bloodstream, quickly reacts with the haemoglobin and is transported around the body. It can combine with oxyhaemoglobin to form methemoglobin and nitrates. Methaemoglobin does not combine with oxygen but, if the blood oxygen is low, it can combine with haemoglobin to form nitrosylemoglobin. A major cause of toxicity from nitric oxide inhalation is hypoxia resulting from the gradual removal of oxygen carrying capacity in the blood due to methaemoglobin formation. The nitric oxide concentrations used for medical treatments depend on the patient and disease but 20 to $80 \mathrm{ppm}$ have been reported for adults and 6 to 20ppm for children (29).

Coma and death can ensue at high methaemoglobin levels. Excessive levels of nitric oxide in blood have been shown to cause low blood pressure. However, it has been reported that tobacco smoke can contain up to 1000ppm of nitric oxide but this does not produce acute mortality.

Sheep haemoglobin was used to study the ability of haemoglobin to combine with nitric oxide. The study used carbon monoxide gas containing $1 \%$ nitric oxide and concluded that nitric oxide has about 1500 times more affinity for haemoglobin than carbon monoxide. The paper also concluded that nitric oxide combines with haemoglobin between 5 and 20 times faster than oxygen and that the resulting compound breaks down slowly.

Medical treatments using nitric oxide have produced methaemoglobin levels of up to, for example, $5 \%$ with exposure to $80 \mathrm{ppm}$ nitric oxide for several hours, but 
results appear to be highly dependant on the patient, the ailment and the duration of treatment. (9) (28).

The effect of nitric oxide inhalation ranges between life saving and therapeutic at low concentration to toxic at high concentrations.(9). Thus at low concentrations, nitric oxide aids breathing and the passage of oxygen into the bloodstream. It is possible that it could also aid the passage of other gases in fire effluents, e.g. isocyanides have been reported to combine with haemoglobin (3). At high concentrations, nitric oxide can be lethal. It has been reported that nitric oxide can have different effects with different species. Thus the exposure of rats to $1500 \mathrm{ppm}$ for 15 minutes and to $1000 \mathrm{ppm}$ for 30 minutes, and of lambs to $80 \mathrm{ppm}$ for 60 to 180 minutes does not cause adverse effects, but the exposure of rabbits to 5ppm for 14 days causes interstitial oedema. Difficulties exist when exposure data from one species is related to another. Work by Kaplan (32) exposed baboons and rats to hydrogen chloride and carbon monoxide and suggested that results for tests with rats may not relate to human exposures.

Nitrogen Dioxide is also a free radical and can exist as a monomer and dimer. It acts as a mixed acid anhydride which dissolves rapidly in water to form acids. The effects of inhaled nitrogen dioxide on bronchial tone and reactivity are controversial but high concentrations are known to cause pulmonary oedema and lethality. Although the in-vivo effects of nitrogen dioxide are still under investigation (8), in-vitro studies indicate that nitrogen dioxide will dissolve in water to form nitric and nitrous acids (32) (34) and that these acids are most likely responsible for the lung edema and death.

A study of the effects of mixtures of nitrogen dioxide and carbon dioxide gases on rats concluded that that the cause of death of the exposed rats was lung edema. The animal showed a dramatic increase in the methaemoglobin in their blood but the oxyhaemoglobin level was unaffected. The paper also concludes that carbon dioxide significantly increases the effect of nitrogen dioxide and the formation of methaemoglobin and that this was due to the action of carbon dioxide as a respiratory stimulant causing hyperventilation (35).

The paper also concluded that carbon dioxide had a synergistic effect and significantly increased the effect of the nitrogen dioxide and the formation of methaemoglobin (35). 
In some toxic potency calculations, the effect of carbon dioxide is taken into account with carbon monoxide (equation 1) but in others (equation 2) it is applied to all the fire effluent constituents.

Published toxicity data, given in table 3 (3) (4) (22) (33) (34), suggests that nitric oxide and nitrogen dioxide will cause significantly different effects when inhaled.

$\begin{array}{lcc}\text { Effect of Exposure } & \begin{array}{c}\text { Nitric Oxide } \\ \text { ppm }\end{array} & \begin{array}{c}\text { Nitrogen Dioxide } \\ \text { ppm }\end{array} \\ \text { TLV (Threshold limit value) } & 25 & 5 \\ \text { Short term max exposure in work place } & 50 & 5 \\ \text { IDLH (Immediate danger to life and health) } & 100 & 100 \\ \text { Very dangerous within } 30 \text { to } 60 \text { minutes } & & 100 \text { to } 200 \\ & & 832 \\ \mathrm{LC}_{50} \text { Rats } 30 \text { mins } \quad 5 \text { min } & & 170-200 \\ \mathrm{LC}_{50} \text { Rats } 30 \text { mins } \quad 30 \text { min } & & 250 \\ \text { Incapacitation }(\mathrm{FEC}=1)_{\mathrm{LC}_{50} \text { Rats } 30 \text { mins } \quad 250 \text { min }} & 870 & \\ \text { No adverse effect } & 1000 & \end{array}$

Table 3. Response of Humans and Rats to Inhaled Nitric Oxide and Nitrogen Dioxide. (3) (4) (24) (35) (36).

In practical terms, the amount of nitrogen dioxide in fire effluents is frequently overstated. Chemical methods often determine the total nitrogen oxides (NOx) and do not distinguish between nitric oxide and nitrogen dioxide. Chemiluminescence meters can determine total nitrogen oxides and, or, nitric oxide which enables nitrogen dioxide to be calculated by subtracting the nitric oxide value from the total value of nitrogen oxides. However, compounds such as hydrogen cyanide, organo-nitriles, etc. can oxidise in the chemiluminescence meter which results in false, high nitrogen dioxide readings. With Fourier Transform Infra Red (FTIR) instruments, nitric oxide and nitrogen dioxide are determined separately.

\section{Stability of Nitrogen Oxides.}

Textbook data (Table 4) suggests that at fire temperatures, nitric oxide is the stable oxide but at less than $200^{\circ} \mathrm{C}$, most of the gas should be nitrogen dioxide $\left(\mathrm{NO}_{2}\right)$ or dinitrogen tetroxide $\left(\mathrm{N}_{2} \mathrm{O}_{4}\right)$. (17). The reaction of nitric oxide with oxygen in air can be demonstrated when nitric oxide is allowed to emerge into air where it immediately changes into the dark red-brown nitrogen dioxide gas. 


$\begin{array}{cccc}\text { Temperature } & \begin{array}{c}\text { Nitric } \\ \text { Oxide } \\ \text { NO }\end{array} & \begin{array}{c}\text { Nitrogen } \\ \text { Dioxide } \\ \mathbf{N O}_{2}\end{array} & \begin{array}{c}\text { Dinitrogen } \\ \text { Tetroxide } \\ \mathbf{N}_{2} \mathbf{O}_{4}\end{array} \\ { }^{\circ} \mathrm{C} & \% & \% & \% \\ 620 & 100 & & \\ 490 & 55 & 45 & \\ 390 & 35 & 65 & \\ 223 & 5.3 & 95 & 20 \\ 154 & & 80 & 40 \\ 100 & & 60 & 60 \\ 49 & & 40 & 89 \\ 27 & & 11 & \end{array}$

Table 4. Relationship between Temperature and the Formation of Nitric Oxide, Nitrogen Dioxide and Dinitrogen Tetroxide. (17).

However, this demonstration is carried out with very high concentrations of nitric oxide. In contrast, fire effluents typically contain less than 1000ppm of nitric oxide while concentrations of less than 100ppm have been observed.

The chemical reactions of nitrogen and oxygen and, in particular that of nitric oxide in air, are many and varied. A detailed review of kinetic data for high temperature reactions has been published (37).

Recent reports show that gaseous mixtures of low concentrations of nitric oxide in air are increasingly used to treat persons with lung disorders (8) (9). Concerns about the stability of nitric oxide in air and the adverse toxic effects of inhaled nitrogen dioxide have led to a number of studies (38) (39) (40).

The rate of conversion of nitric oxide to nitrogen dioxide is given by the equation:

$$
d[N O] / d t=2 k[N O]^{2} /\left[\mathrm{O}_{2}\right] \quad \text { Equation } 3
$$

Because the concentration of nitric oxide is relatively small (volume ppm) compared to the oxygen concentration (percent), the oxygen concentration will remain essentially constant and integrating this equation will give:

$$
1 /[N O]_{t}-1 /[N O]_{i}=2 k\left[O_{2}\right] t
$$


where $\mathrm{k}$ is a constant which depends on whether the reaction takes place in air or water. (36) (38).

Table 5 shows the range of values of $\mathrm{k}$ published by various workers from the relationship between nitric oxide $\left[\mathrm{NO}^{-1}\right.$ and time (minutes) after the gas was mixed with oxygen at $25^{\circ} \mathrm{C}$.(38) (39) (40).

\begin{tabular}{|c|c|c|c|}
\hline Value of $\mathbf{k}$ for equations $3 \&$ & Temperature & Relative & Reference \\
\hline $\mathrm{cm}^{6}$ moleculess ${ }^{-2} \mathrm{~s}^{-1}$ & ${ }^{\circ} \mathrm{C}$ & Humidity \% & \\
\hline $5.22 \times 10^{-38}$ & 20 & 100 & Bouchet et al \\
\hline $1.57 \times 10^{-38}$ & 23 & NA & Glasson \\
\hline $2.27 \times 10^{-38}$ & 25 & 0 & Miyamoto et al \\
\hline $2.27 \times 10^{-38}$ & 25 & 40 & Miyamoto et al \\
\hline $2.27 \times 10^{-38}$ & 25 & 90 & Miyamoto et al \\
\hline $1.93 \times 10^{-38}$ & 27 & NA & Foubert et al \\
\hline $1.89 \times 10^{-38}$ & 37 & 40 & Miyamoto et al \\
\hline $5.39 \times 10^{-38}$ & 37 & 100 & Bouchet et al \\
\hline
\end{tabular}

Table 5. Reported Values for the Reaction Rate Constant for the Conversion of Nitric Oxide to Nitrogen Dioxide.

A detailed study investigated the effects of low initial nitric oxide concentration, oxygen concentration and nitrogen dioxide formation on the conversion of nitric oxide to nitrogen dioxide (41). It also reports that the presence of small concentrations of olefins does not affect the generation of nitrogen dioxide from nitric oxide.

Table 6 shows reported times required to generate a low concentration (typically $5 \mathrm{ppm}$ ) of nitrogen dioxide from mixtures of nitric oxide and oxygen at ambient conditions. 


$\begin{array}{ccccc}\begin{array}{c}\text { Initial } \\ \text { Nitric } \\ \text { Oxide } \\ \text { Concentration }\end{array} & \begin{array}{c}\text { Final } \\ \text { Nitrogen } \\ \text { Dioxide } \\ \text { ppm }\end{array} & \begin{array}{c}\text { Duration of } \\ \text { Assessment } \\ \text { Period }\end{array} & & \text { Reference } \\ 10 & \text { ppm } & \text { mins } & & \\ 20 & 5 & 139 & \text { Bouchet } & 39 \\ 20 & 5 & 60.1 & \text { Foubert } & 38 \\ 20 & 5 & 36.4 & \text { Miyamoto } & \text { Est. from } 40 \\ 28 & 5 & 23.1 & \text { Bouchet } & 39 \\ 30 & 2.2 & 600 & \text { Law-Roune } & 42 \text { from } 8 \\ 40 & 5 & 9.3 & \text { Bouchet } & 37 \\ 40 & 5 & 12.9 & \text { Foubert } & 38 \\ 40 & 5 & 10.0 & \text { Miyamoto } & \text { Est. from } 40 \\ 50 & 5 & 5.0 & \text { Bouchet } & 39 \\ 56 & 5 & 1.0 & \text { Bouchet } & 37 \\ 60 & 2.2 & 600 & \text { Law-Roune } & 42 \text { from } 8 \\ 80 & 5 & 2.1 & \text { Bouchet } & 39 \\ 80 & 5 & 3.0 & \text { Foubert } & 38 \\ 100 & 5 & 1.2 & \text { Bouchet } & 39 \\ 120 & 5 & 0.7 & \text { Bouchet } & 39 \\ & 5 & 1.3 & \text { Foubert } & 38\end{array}$

Table 6. Reported Times for Nitric Oxide and Oxygen Mixtures to Generate Low Concentrations (2.2 ppm or 5 ppm) of Nitrogen Dioxide (38) (39) (estimated from 40) (42).

Figure 3 shows the gradual formation of nitrogen dioxide from nitric oxide for gas/oxygen/nitrogen mixtures held at temperatures between $20 \mathrm{C}$ and $37 \mathrm{C}$ and between $0 \% \mathrm{RH}$ and $100 \% \mathrm{RH}$. The nitric oxide concentrations were approximately 100 to $120 \mathrm{ppm}$. The figure shows that nitric oxide remains in significant concentrations for a considerable time after the mixture was generated.

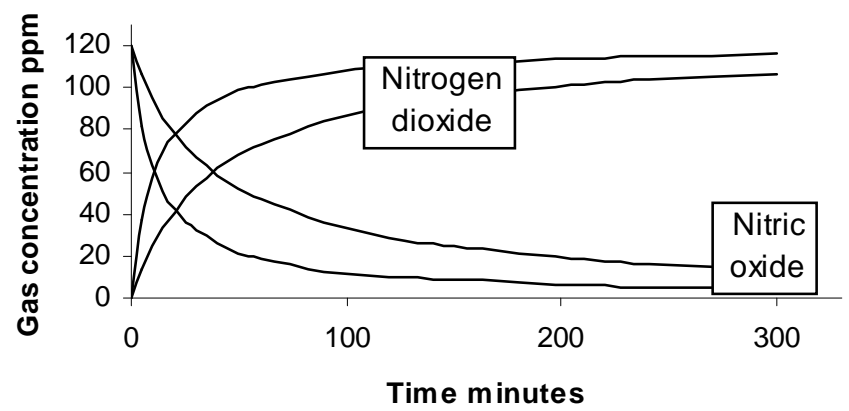

Figure 3. Formation of nitrogen dioxide from nitric oxide. 
Note to Figure 3. The concentration bands have been constructed from published data for tests with approximately $120 \mathrm{pp}$, nitric oxide between $20 \mathrm{C}$ to $37 \mathrm{C}$ and $0 \%$ to $100 \%$ RH.

These data show different results for the conversion of nitric oxide to nitrogen dioxide at low concentrations in air and it has been suggested that results may depend on experimental conditions and the assumptions made in the calculations. It has also been reported (40) that the rate of conversion of nitric oxide to nitrogen dioxide is increased by increasing oxygen concentrations, that humidity does not have a significant effect and that the rate of formation of nitrogen dioxide is faster at lower temperatures, that is it is faster at $25^{\circ} \mathrm{C}$ than at $37^{\circ} \mathrm{C}$. There appears to be a possible discrepancy between the results quoted in different papers.

These reported data show that it is possible for nitric oxide to exist at low concentrations and at low (inhalation) temperatures for a significant period. The presence of nitric oxide at relatively low temperatures and concentrations is perhaps not surprising since the reaction of nitric oxide with oxygen requires the presence of one molecule of oxygen and two of nitric oxide and it would be reasonable to expect this reaction to proceed more slowly at the low concentrations of nitric oxide.

Textbook data (17), given in table 7 , shows that, at $8^{\circ} \mathrm{C}$, nitric oxide is sparingly soluble in water and that its solubility is similar to that of oxygen and nitrogen (see table 7). Even though fire effluents contain large amounts of water, it is likely that the nitric oxide in fire effluents will be inhaled as a gas.

\section{Gas}

Nitric oxide $\left(8^{\mathrm{O}} \mathrm{C}\right)$

Oxygen

Nitrogen

Nitrogen Dioxide
Solubility in water

$\%$

6

4

2

Highly soluble

Table 7. Solubility of Gases in Water (17).

\section{Discussion, Conclusions and Recommendations.}

The nitrogen oxide formed in fire is nitric oxide. It is produced by the reaction of nitrogen and oxygen at high temperatures and by the combustion of materials containing nitrogen. The reactions of nitric oxide in air are many and complex (37) 
but nitric oxide will gradually oxidize to nitrogen dioxide. The rate of formation of nitrogen dioxide is affected by a number of factors. The rate decreases with decreasing nitric oxide concentration and with decreasing oxygen concentration. It also decreases with decreasing temperature although some evidence shows that at low ambient temperatures, the rate may increase.

The composition of a fire effluent inhaled by persons within a fire environment is affected by a number of factors including the nature of the burning materials, the fire environment, both locally and remote from the seat of the fire, the ventilation of the fire enclosure, dilution of the smoke and the distance from the fire. As the fire effluent moves away from the seat of the fire, it will be cooled by contact with the surfaces of the fire enclosure and will be diluted by the entrainment of air especially as it passes beneath lintels, etc. Solid particles, e.g. soot, will be deposited on the floor and walls while soluble gases such as hydrogen chloride will dissolve in water vapour and droplets as they condense onto cool walls and floors. The distance between the seat of the fire and the exposure site and the flow of the effluent stream will affect the time available for chemical reactions which take place in the effluent stream. The effluent temperature will be affected by cooling and will affect the rates of chemical reactions. All of these factors can affect the composition and concentration of the fire effluent to which trapped or escaping persons are exposed. Within the context of this paper, these factors will affect the relative concentrations of nitric oxide and nitrogen dioxide in the inhaled fire effluent and hence their toxic effects.

The inherent toxicity of nitric oxide and nitrogen dioxide are very different and consequently the effects of inhaling fire effluents containing these gases will depend on the relative amounts of each gas in the effluent.

Nitrogen dioxide acts as a mixed acid anhydride and rapidly dissolves in water to form strong, highly irritant and corrosive acids. The immediate effect of exposure will be intense irritation of eyes, throat, lungs, etc. and serious damage to lungs which may result in death even after the exposure period has ceased.

In contrast, nitric oxide will remain undissolved and will be inhaled as a gas. On its own and at low concentrations, the effects of nitric oxide can be life saving and therapeutic but it is toxic at higher concentrations. The therapeutic effects are due to vasodilation which aids the passage of oxygen into the bloodstream but while 
beneficial in controlled medical treatments, this effect could possibly aid the transfer of other fire effluent components, e.g. isocyanides, into the bloodstream to cause potential toxic effects. Nitric oxide is also absorbed into the bloodstream and will combine with haemoglobin to form methemoxyhaemoglobin in a similar manner to that of carbon monoxide forming carboxyhaemoglobin. High concentrations of nitric oxide can lead to coma and death especially with reduced oxygen and high carbon monoxide levels. It can also cause massive vasodilation and low blood pressure.

The toxic effects of nitric oxide are highly complex but this situation will become even more complex when nitric oxide is mixed with different amounts of nitrogen dioxide. This will occur as the fire effluent ages and the nitric oxide gradually forms nitrogen dioxide.

The Toxfire report (22) suggests that the potential risks for humans inhaling the more or less undiluted smoke gases from the room tests can be obtained by comparing the mean, measured gas concentrations determined in the room opening, to hazard reference values. Toxfire suggests hazard levels using the hygienic limit values for 15 minute exposures (22) (see table 3) although these are significantly lower than the reference values used to calculate hazard levels in ISO documents. (3)(4). Table 8 shows the average concentrations for nitric oxide and nitrogen dioxide determined in the room opening of the Toxfire ISO room tests.

\begin{tabular}{|c|c|c|c|c|}
\hline Equivalence Ratio & $<\mathbf{1}$ & $>\mathbf{1}$ & $<1$ & $>1$ \\
\hline Fire Gas & Nitric & e ppm & Nitrog & de ppm \\
\hline Material & & & & \\
\hline Polypropylene & 16 & 25 & 2 & 2 \\
\hline Nylon 6.6 & 80 & 270 & 4 & 14 \\
\hline Tetramethyl thiuram monosuphide & 320 & 210 & 4 & 6 \\
\hline 3-Chloro-4 nitrobenzoic acid & 1900 & 130 & 12 & 3 \\
\hline Chlorobenzene & 9 & & $<1$ & \\
\hline
\end{tabular}

Table 8. Mean Concentrations (ppm) of Nitric Oxide and Nitrogen Dioxide in the opening of the ISO room for Different Ventilation Scenarios. (22).

These data suggest that nitric oxide will be the predominant nitrogen oxide in fire effluents within the room of origin of the fire and in its immediate proximity. 
However, as the effluent flows away from the fire zone, so nitric oxide concentration will decrease, partly due to dilution caused by ventilation and air entrainment and partly by its gradual oxidation to nitrogen dioxide. The relative amounts of nitric oxide and nitrogen dioxide in the inhaled fire effluent will therefore depend on many factors relating to the fire dynamics, the fire environment and the distance of the inhalation site from the fire. In real fire situations, the time required for the nitrogen dioxide concentration to reach a specific hazard level will also depend on these factors.

Table 9 shows the times for different initial concentrations of nitric oxide to generate various hazard levels of nitrogen dioxide. The initial nitric oxide concentrations selected were the average, plateau concentration (400ppm) for the test shown in Figure 1 and the average concentrations given in table 8 for the full scale fire tests with polypropylene and nylon $6.6,(22)$

The concentrations selected for nitrogen dioxide were the short term, maximum allowable concentrations in the workplace (5 ppm) (22) and the $\mathrm{LC}_{50}$ $(170 \mathrm{ppm})(3)$ and $\mathrm{FEC}=1(250 \mathrm{ppm})(4)$ values. The latter two values relate to inhalation periods of 30 minutes.

The times to generate the hazard levels given in table 9 have been extrapolated from published data (38)(39) and refer to ambient temperatures. It must be acknowledged that extrapolation of data significantly beyond experimental data points is unsound. However the data in table 9 has been included to illustrate that nitric oxide can exist in fire effluents for a significant time and to highlight the need for further studies in this area.

These times are extrapolated from published data (38) (39) and refer to ambient temperatures. Although the published relationship between nitric oxide concentrations and decay time is a straight line, it must be acknowledged that extrapolation of data significantly beyond experimental data points is unsound but the data in table 9 has been included to illustrate that nitric oxide can exist in fire effluents for a significant time and the highlight the need for further studies in this area. 


\begin{tabular}{|c|c|c|c|c|c|}
\hline \multicolumn{3}{|c|}{ Gas Concentrations } & \multirow{2}{*}{\multicolumn{3}{|c|}{$\begin{array}{c}\text { Time } \mathrm{x} \text { minutes to form hazard } \\
\text { concentrations of } \mathrm{NO}_{2}\end{array}$}} \\
\hline & \multicolumn{2}{|c|}{ Composition after $\mathbf{x}$ mins } & & & \\
\hline \multirow{3}{*}{$\begin{array}{l}\text { Nitric } \\
\text { Oxide } \\
\text { ppm }\end{array}$} & \multirow{3}{*}{$\begin{array}{c}\text { Nitric } \\
\text { Oxide } \\
\text { ppm }\end{array}$} & \multirow{3}{*}{$\begin{array}{c}\text { Nitrogen } \\
\text { Dioxide } \\
\text { ppm }\end{array}$} & \multirow{2}{*}{\multicolumn{3}{|c|}{$\begin{array}{l}\text { extrapolated from } \\
\text { published base data }\end{array}$}} \\
\hline & & & & & \\
\hline & & & minutes & & minutes \\
\hline \multicolumn{6}{|c|}{ Hazard concentration $\mathrm{NO}_{2}=5 \mathrm{ppm}(22)$} \\
\hline 25 & 20 & 5 & 14 & to & 32 \\
\hline 80 & 75 & 5 & 1.2 & to & 2.7 \\
\hline 270 & 265 & 5 & 0.1 & 0.22 & 0.22 \\
\hline 400 & 395 & 5 & 0.04 & 0.1 & 0.1 \\
\hline \multicolumn{6}{|c|}{ Hazard concentration $\mathrm{LC}_{50}$ value for $\mathrm{NO}_{2}=170 \mathrm{ppm}(3)$} \\
\hline 270 & 100 & 170 & 8.7 & to & 20 \\
\hline 400 & 230 & 170 & 2.6 & to & 5.9 \\
\hline \multicolumn{6}{|c|}{ Hazard concentration FEC $=1$ for $\mathrm{NO}_{2}=250 \mathrm{ppm}(4)$} \\
\hline 270 & 20 & 250 & 64 & to & 149 \\
\hline 400 & 150 & 250 & 5.8 & to & 13 \\
\hline
\end{tabular}

Table 9. Times for Different Concentrations of Nitric Oxide to form Hazardous Concentrations of Nitrogen Dioxide at Ambient Temperature extrapolated from published data (38) (39).

It is therefore possible that persons exposed to fire effluents close to the origin of a fire will inhale a relatively high proportion of nitric oxide whereas persons exposed to the effluent a significant time and distance from the fire will be exposed to a relatively high concentration of nitrogen dioxide. For the reasons given above the toxic hazards and hence the effects of inhalation of these two effluents will differ significantly.

Methods of calculating toxic potency from chemically determined fire effluent compositions are given in ISO documents (3)(4) and earlier in this paper. In these methods, all nitrogen oxides are considered to be nitrogen dioxide and the equations do not include terms for nitric oxide. However, nitric oxide can occur in significant concentrations in some fire effluents and, since the toxic hazards of nitric oxide differ significantly from those of nitrogen dioxide, these equations do not relate to all scenarios. It is suggested that a term is required to allow for the effects of nitric oxide.

\section{Conclusions and Recommendations.}

The assessment of fire smoke toxicity is an essential part of any fire hazard analysis. The current practice of treating all nitrogen oxides as nitrogen dioxide may represent a worse scenario. While this may be acceptable as a temporary measure, the observations made in this paper suggest that nitric oxide will be present in significant 
quantities in some fire effluents and particularly in effluents close to the fire. The relative proportion of nitric oxide will decrease and that of nitrogen dioxide will increase with increasing time and distance from the fire. This has implications for the determination of fire gases and the calculation of fire smoke toxic potency values such as FEC, FED and $\mathrm{LC}_{50}$. All nitrogen oxides are currently considered to be nitrogen dioxide, a highly acid irritant, but, because in some situations, the predominant nitrogen oxide may be nitric oxide, the current methods of calculating toxic potency may need to be reconsidered. The chemical reactions and toxicity of nitric oxide are extremely complex and need to be taken into account together with relevant fire parameters as part of a fire risk assessment.

It is recommended that the information given in this paper should be extended with additional data from real scale fire tests and the complex chemical reactions and the toxicity of nitric oxide should be investigated with a view to improving the accuracy and reliability of the methods used to calculate the toxic potency of fire effluents.

\section{References.}

$1 \quad$ ISO TS 19706:2004 Guidelines for assessing the fire threat to people.

2 Council Directive 86/609/EEC of 24 November 1986 on the approximation of laws, regulations and administrative provisions of the Member States regarding the protection of animals used for experimental and other scientific purposes.

3 ISO 13344:2004, Estimation of the lethal toxic potency of fire effluents

4 ISO/TS 13571:2002, Life-threatening components of fire - Guidelines for the estimation of time available for escape using fire data.

5 SAFIR, An International Programme to Investigate the Use of FTIR to Analyse Fire Effluents, VTT Building Technology, Espoo, Finland, 1999.

$6 \quad$ K.T.Paul, Use of FTIR to analyse fire gases from burning rubbers and plastics, $\quad$ Flame Retardants; 94. BPF, London, 1994. 
7 K.T.Paul, Use if FTIR to analyse fire gases from burning polyurethane foams, Cellular Polymers III Conference, Coventry, 1995.

8 B.K.Kavenagh, R.G.Pearl, Inhaled nitric oxide in Anesthesia and critical care medicine. International Anesthesiology Clinics, Vol. 333, No 1, 1995.

9 Adverse effects and toxicity of inhaled nitric oxide, D.R.Hess., Respiratory Care, March 1999, Vol 44, No 3 pp315 to 3302

10 Inhaled cigarette smoke selectively reverses human hypoxic vasoconstriction. P.M. Dupuy, J.P. Lancon, M. Francoise, C.G. Foster, Intensive Care Med, 1995; 21, (11), 941-944.

11 Pulmonary effects of endogenous and exogenous nitric oxide in the pig: relation to cigarette smoke inhalation. K. Alving, C. Fornhem, J.M. Lundberg, Br J Pharmacol 1993;110(2):739-746.

12 Vascular effects of cigarette smoke in isolated pig lungs. M.J. Oilman, J.T. Sylvester, I.P. Kennedy, H.A. Menkes, R.J. Traystman, Am. Rev. Respir. Dis. $1981 ; 124(5),: 549-553$.

13 Cigarette smoke causes acute fluctuations in the cyclic GMP content of the isolated intact lung. M.B. Maron, T.D. Crowe, J.M. Braughler,. Respiration, $1984 ; 45(1), 39-44$.

14 Nitrogen oxides in tobacco smoke. V. Norman, C.H. Keith,. Durham: Liggett \& Myers Tobacco Co, 1965.

15 Quality and applications of fuels, motor oils, and additives in foreign countries (report on the seventh world petroleum congress), K. K. Papok, A. B. Vipper, Chemistry and Technology of Fuels and Oils, Vol. 3,1967, pp 603-606.

16 Yannick Le Tallec, Debbie Smith, John Hunter, Frederik R. Groenevald, Evaluation of Toxicants for Materials used in military vehicles and equipment. Interflam July 2000, Edinburgh, Interscience Publications. 
17 F.A.Filbrick and E.J.Holmyard, A Textbook of Theoretical and Inorganic Chemistry, J.M.Dent and Sons, London. 1946.

18 M.J.Pilling and P.W.Seakins, Reaction Kinetics, Oxford Publications, 1995.

19 F.A.Cotton and G.Wilkinson, Advanced Inorganic Chemistry, Interscience Publishers, New York, 1972.

20 ISO 19701:2005, Methods for sampling and analysis of fire effluents.

21 ISO 19702:2006, Toxicity testing of fire effluents - Guidance for analysis of gases and vapours in fire effluents using FTIR gas analysis.

22 Toxfire, Fire characteristics and smoke gas analysis to under-ventilated large scale combustion experiments, Test in the ISO 9705 Room. A Lonnermark, P. Blomqvist, M.. Mansson, H, Person. M. Simmonson, SP Report 1996:45. Boras, Sweden, 1997.

23 IEC 60695 Fire Hazard testing - Part 7-50: Toxicity of fire effluentsEstimation of toxic potency: Apparatus and test method.

24 IEC 60695 Fire hazard testing - Part 7-51: Toxicity of fire effluent Estimation of toxic potency: Calculation and interpretation of test results.

25 ISO TS 19700:2006 Controlled Equivalence Ratio Method for the Determination of Hazardous Components of Fire Effluents

26 ISO 5660-1:1993 Fire tests - Reaction to fire - Part 1: Rate of heat release from building products (cone calorimeter method).

27 IMO MSC.41(64), Interim standard for measuring smoke and toxic products of combustion, International Maritime Organisation.

28 Private communication, P. Blomqvist, Swedish National Testing and Research Institute, Borose, Sweden.

29 J. Tibballs, Clinical applications of gaseous nitric oxide. Anaesth. Intensive Care, 1993: 21, 866-871 
30 INOmax for Inhalation, 100 and 800ppm.INO Therapeutics Inc. Clinton, N.J. USA.

31 Q.H.Gibson, F.J.W. Roughton, The kinetics of equilibria of the reactions of nitric oxide with sheep haemoglobin. J Physiol. London, 1957:136:507-526

32 Kaplan H.L., Effects of irritant gases on avoidance/escape performance and respiratory response of the baboon. Toxicology, 47, 165-179, 1987.

33 T.L.Guidotti, The higher oxides of nitrogen, inhalation toxicology. Environmental Research, 15, 443-472, 1978.

34 E.Goldstein, F.Goldstein, N.F.Peek, N.J.Parks, Absorbtion and Transport on nitrogen oxides, Nitrogen Oxides and their effect on health ED. S.D.Lee, Arbor Science, Ann Arbor, pp143-160. 1980.

35 B.C.Levin, M.Paabo, L.Highbarger, N.Eller, Synergistic effects of nitrogen dioxide and carbon dioxide following acute inhalation exposure of rats. NSTIR 89-4105, NIST Gaithesbuer, USA. 1989.

36 C.J.Hilado, Flammability Handbook for Plastics. Technomic, USA.

37 D.L.Baulch, D.D.Drysdale, Evaluated kinetic Data for High Temperature Reactions. Butterworths, London, 1973.

38 L..Foubert, B..Fleming, R. Latimer et.al. Safety guidelines for use of nitric oxide (letter), Lancet, 1992, 16+15-1616. 339, 1992.

39 M.Boucher, M.Radnaudin, C.Raveau, et.al. Safety requirements fir inhaled nitric oxide in nconates. (letters) Lancet, 1993. 341. 968-969.

40 K. Miyamoto, A. Aida, M. Nishinura, et al. Effects of humidity and temperature on nitrogen dioxide formation from nitric oxide (letter). Lancet 1994, 343:1099-1100.

41 W.A.Glasson, C.S.Tuesday, The atmospheric oxidation of the higher oxides of nitric oxide. J.Am. Chem.Soc. 1963,85, (5) 2901-2904. 
42 J.D.Law-Roune, N.Montafis, M.Fischler, Production of NO2 during nitric oxide (NO) inhalation (abstract) Intensive.Care Med. 1992, 18, 867 